\title{
Defecation Frequency and Stool Form in a Coastal Eastern Indian Population
}

\author{
Manas Kumar Panigrahi, ${ }^{1}$ Sanjib Kumar Kar, ${ }^{1}$ Shivaram Prasad Singh ${ }^{1 *}$ and Uday C Ghoshal ${ }^{2}$ \\ ${ }^{1}$ Department of Gastroenterology, S. C. B. Medical College, Cuttack, Odisha, India; and ${ }^{2}$ Sanjay Gandhi Postgraduate Institute of Medical \\ Sciences, Lucknow, India
}

\section{Background/Aims}

Data on normal stool form and frequency, which are important for defining constipation, are scanty; hence, we studied these in an eastern Indian population.

\section{Methods}

One thousand and two hundred apparently healthy asymptomatic subjects were evaluated for predominant stool form (Bristol chart with descriptor) and frequency. Data on demographic and life-style (diet and physical activity) were collected.

Results

Of 1,200 subjects (age $42 \pm 14.5$ years, 711, 59\% male), most passed predominantly Bristol type IV stool (699 [58.2\%]; other forms were: type I (23 [1.9\%]), type II (38 [3.2\%]), type III (99 [8.2\%]), type V (73 [6\%]), type VI (177 [14.7\%]), type VII (7 $[0.6 \%])$ and an irregular combination $(84[7 \%])$. Weekly stool frequency was $12.1 \pm 4.7$ (median 14, range 2-42). Less than 3 stools/week was noted in 32/1,200 $(2.6 \%)$. Female subjects $(n=489)$ passed stools less frequently than males $(n=711)$ $(11.1 \pm 5.6 /$ week vs. $12.8 \pm 3.8 /$ week, $P<0.001)$ and tended to pass harder forms (type I: 17 , type II: 20, type III: 39 vs. $6,18$ and 60 , respectively, $P=0.061)$. Vegetarians $(n=252)$ and physically active $(n=379)$ subjects tended to pass stool more frequently than occasional $(n=553)$ and regular non-vegetarian $(n=395)(11.8 \pm 4.5$ and $12.8 \pm 4.7$ vs. $11.3 \pm$ 4.7; $P<0.05)$ and sedentary $(n=464)$ and intermediately active $(n=357)$ subjects $(13.4 \pm 4.0$ and $12.3 \pm 4.5$ vs. 10.9 $\pm 5.1, P=0.080$ ) in different age groups, respectively. Older age was associated with less frequent stool, particularly among female population. Female gender and age $>35$ years were significant on multivariate analysis.

\section{Conclusions}

Median stool frequency in the studied population was 14/week (range 2-42) and predominant form was Bristol type IV. Older age was associated with lesser stool frequency, particularly among female subjects.

\section{(J Neurogastroenterol Motil 2013;19:374-380)}

Key Words

Constipation; Functional gastrointestinal disorder; Gastrointestinal transit; Irritable bowel syndrome

Received: February 24, 2013 Revised: June 1, 2013 Accepted: June 1, 2013

(c) This is an Open Access article distributed under the terms of the Creative Commons Attribution Non-Commercial License (http://creativecommons. org/licenses/by-nc/3.0) which permits unrestricted non-commercial use, distribution, and reproduction in any medium, provided the original work is properly cited.

*Correspondence: Shivaram Prasad Singh, MD

Department of Gastroenterology, S.C.B. Medical College, Cuttack, Odisha 753007, India

Tel: +91-671-2323624, Fax: +91-671-2429195, E-mail: scb_gastro_dept@hotmail.com

Financial support: None.

Conflicts of interest: None.

Author contributions: Manas Kumar Panigrahi collected data and wrote the first draft of the paper. Sanjib Kumar Kar collected data and helped to write the first draft of the paper. Shivaram Prasad Singh designed the study, supervised the work, collected data, analyzed data, helped in writing and editing the paper. Uday C Ghoshal designed the study, analyzed data and extensively edited the paper. 


\section{Introduction}

There are limited data on stool form and frequency among healthy subjects, which are important for defining constipation; most studies available in the literature on this issue are from Western populations. ${ }^{1-5}$ Bowel habits of different population may vary widely due to several factors including dietary habit, quantity of fiber intake and difference in gut transit time. ${ }^{6-8}$ Data on normal bowel habit in different populations are important to define abnormalities in this function, which is the basis for definition of constipation. In the Western population, a stool frequency between 3-21/week is considered normal. ${ }^{1,9}$ This was the basis for an earlier frequency-based definition of constipation, which mentioned that a stool frequency less than 3 per week should be considered as constipation. ${ }^{10}$ However, this definition may not apply to a non-Western population, where a large proportion of patients with irritable bowel syndrome remained unclassified into either constipation or diarrhea using a stool frequency-based criteria. $^{7,11-13}$

A few studies reported that mean stool frequency is higher in several Asian populations (e.g., Beijing, China 7.09/week, Iran 12.5-14/week). ${ }^{14,15}$ There is no data on stool form and only a few studies on frequency in Indian population. ${ }^{11,16}$ Diet of Indian population is quite different from many other regions of the world. Vegetarianism, which is associated with higher fiber intake, is common in India. ${ }^{17}$ A study from northern India showed that mean fecal weight among 514 healthy subjects older than 15 years was $311 \mathrm{~g} / 24$ hour, a value much higher than that in Western population. ${ }^{16}$ It is therefore, important to study stool frequency and form in Indian population in relation to their dietary habit. Accordingly, the present study was undertaken with the following aims: (1) to evaluate the stool form and frequency among general adult population in coastal eastern India and (2) to study relationship between demographic (age, gender) and life-style (diet, physical activity) variables and bowel habit.

\section{Materials and Methods}

\section{Methods}

In this prospective study, conducted at Cuttack, Orissa (Fig. 1) from January 2011 to July 2012, 1,200 apparently healthy asymptomatic subjects were interviewed using questionnaire earlier used for a multi-centric study (MIIBS) ${ }^{18}$ after informed

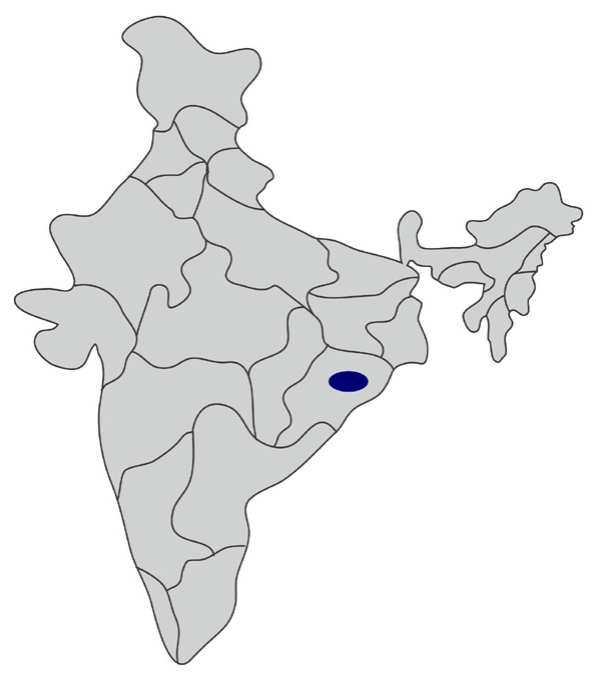

Figure 1. Map of India showing the study area.

consent. Each subject was interviewed to record their demographic (age, gender), life-style parameters (diet, physical activity) and stool frequency and form (using Bristol stool chart containing pictures as well as descriptors). ${ }^{19}$ Dietary habit was recorded as vegetarian (those who do not consume any animal items except milk and its products) and non-vegetarian (those who consume animal products); non-vegetarians were further classified as occasional or regular (almost daily). Levels of physical activity of subjects were classified as active (e.g., manual laborers), intermediately active (people doing exercise $\geq 3$ days/week) and sedentary life style.

\section{Statistical Methods}

Data were checked for normal distribution using ShapiroWilk test. Categorical and continuous data were presented as proportion and mean, standard deviation and $95 \%$ confidence intervals, respectively. Chi-square and unpaired $t$ tests were used to compare between categorical and continuous data, respectively. Weekly stool frequency in different age group in relation to gender, dietary habit and physical activity was compared using Poisson regression. For multivariate analysis, stepwise logistic regression method was used. $P$-values below 0.05 were considered significant for all statistical analysis. Statistical analysis was done using R, Epicalc and R-studio software ( $\mathrm{R}$ development core team, Vienna, Austria) and SPSS version 15 (SPSS, Inc., Chicago, IL, USA). 


\section{Results}

Of 1,200 subjects (age $42 \pm 14.5$ years, range $18-70$ years),

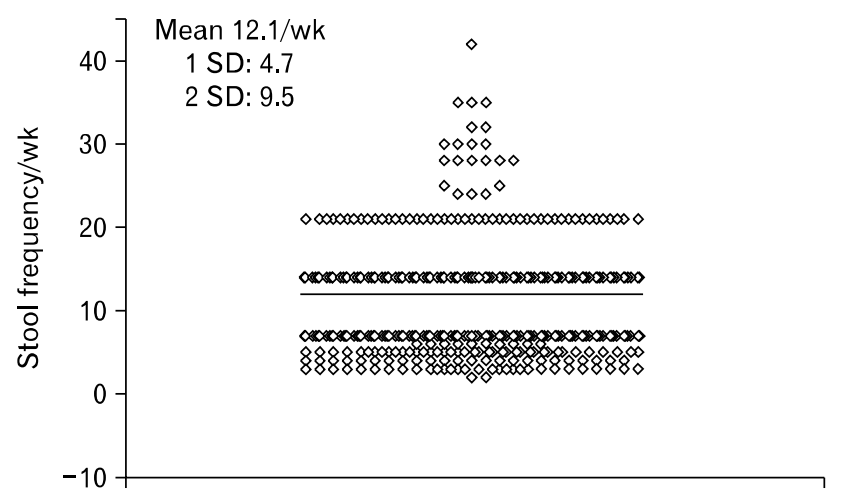

Figure 2. Dot plot showing weekly stool frequency of 1,200 apparently healthy subjects from eastern India. The horizontal line represents mean value.
$711(59 \%)$ were male and $489(41 \%)$ were female. Weekly stool frequency was 12.1 (1 SD 4.7, 2 SD 9.5, Fig. 2; median 14, range 2-42). Most people passed predominantly Bristol type IV stool (699 [58.2\%]); other stool forms were: type I (23 [1.9\%]), type II (38 [3.2\%]), type III (99 [8.2\%]), type V (73 [6\%]), type VI (177 [14.7\%), type VII (7, 0.6\%) and an irregular combination $(84,7 \%)$. Of 1,200 people, 32 (2.6\%) passed less than 3 stools/week, 24 (2\%) between 3-4 stools/week, 40 (3.3\%) between 4-5 stools/week and 10 (0.8\%) between 5-6 stools/week.

\section{Relationship Between Gender, Age and Stool Frequency and Form}

Table shows stool frequency and forms in relation to gender. Female population had lesser frequency and harder forms of stool than male. Stool frequency was lesser among people of older age ( $>35$ years) than among those with younger age $(\leq 35$ years, Fig. 3A). Reduction in stool frequency with older age $(>35$ years) was more among female than among male populations (Fig. 3B). Reduction in stool frequency was noted to start in

Table. Demographic, Life-style and Bowel Pattern of 1,200 Subjects in Relation to Gender

\begin{tabular}{|c|c|c|c|}
\hline & Female $(\mathrm{n}=489)$ & Male $(\mathrm{n}=711)$ & $P$-value \\
\hline Age $($ mean $\pm \mathrm{SD}, \mathrm{yr})$ & $39.3 \pm 12.3$ & $43.8 \pm 15.6$ & $<0.001$ \\
\hline \multicolumn{4}{|l|}{ Stool frequency } \\
\hline$>21 / \mathrm{wk}$ & $12(2.5)$ & $9(1.3)$ & \multirow[t]{6}{*}{$<0.001$} \\
\hline 3/day & $16(3.3)$ & $31(4.4)$ & \\
\hline 2/day & $252(51.5)$ & $506(71.2)$ & \\
\hline 1/day & $115(23.5)$ & $153(21.5)$ & \\
\hline$>3 / \mathrm{wk}$ & $62(12.7)$ & $12(1.7)$ & \\
\hline$\leq 3 / \mathrm{wk}$ & $32(6.5)$ & $0(0)$ & \\
\hline Number per week (mean $\pm \mathrm{SD})$ & $11.1 \pm 5.7$ & $12.8 \pm 3.8$ & $<0.001$ \\
\hline \multicolumn{4}{|l|}{ Bristol stool forms } \\
\hline Type 1 & $17(3.5)$ & $6(0.8)$ & \multirow[t]{7}{*}{$<0.001$} \\
\hline Type 2 & $20(4.1)$ & $18(2.5)$ & \\
\hline Type 4 & $243(49.7)$ & $456(64.1)$ & \\
\hline Type 5 & $31(6.3)$ & $42(5.9)$ & \\
\hline Type 6 & $88(18)$ & $89(12.5)$ & \\
\hline Type 7 & $3(0.6)$ & $4(0.6)$ & \\
\hline An irregular combination & $48(9.8)$ & $36(5.1)$ & \\
\hline \multicolumn{4}{|l|}{ Physical activity } \\
\hline Active & $43(8.8)$ & $336(47.3)$ & \multirow[t]{3}{*}{$<0.001$} \\
\hline Sedentary & $284(58.1)$ & $180(25.3)$ & \\
\hline Intermediate & $162(33.1)$ & $195(27.4)$ & \\
\hline \multicolumn{4}{|l|}{ Diet } \\
\hline Vegetarian & $76(15.5)$ & $176(24.8)$ & \multirow[t]{3}{*}{$<0.001$} \\
\hline Non-vegetarian & $198(40.5)$ & $197(27.7)$ & \\
\hline Occasional non-vegetarian & $215(44)$ & $338(47.5)$ & \\
\hline
\end{tabular}


A

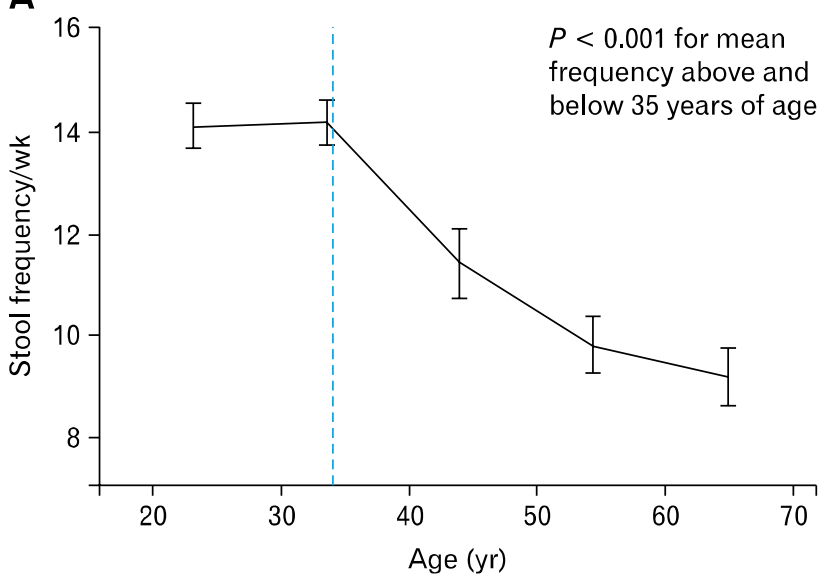

C

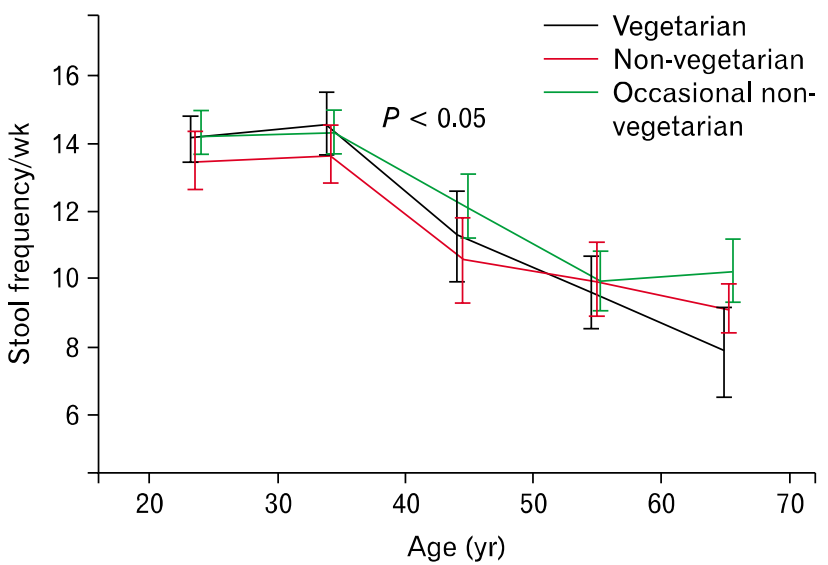

B

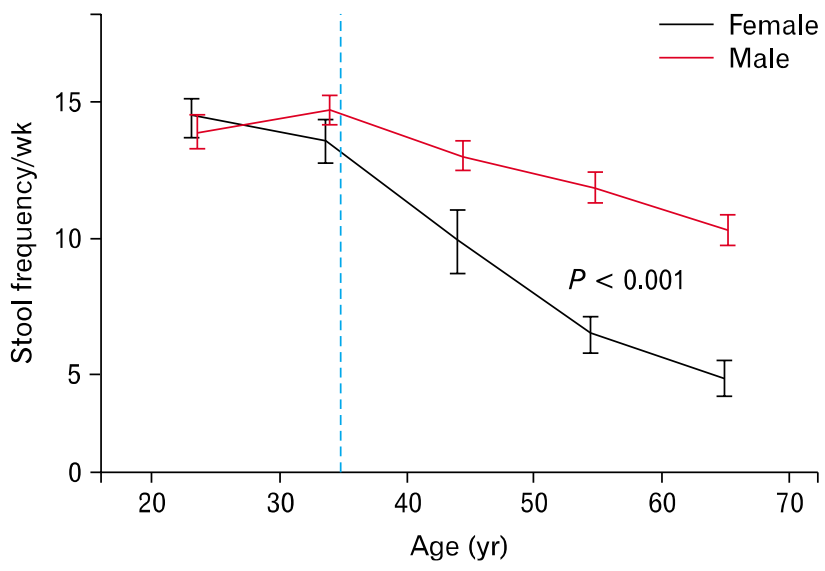

D

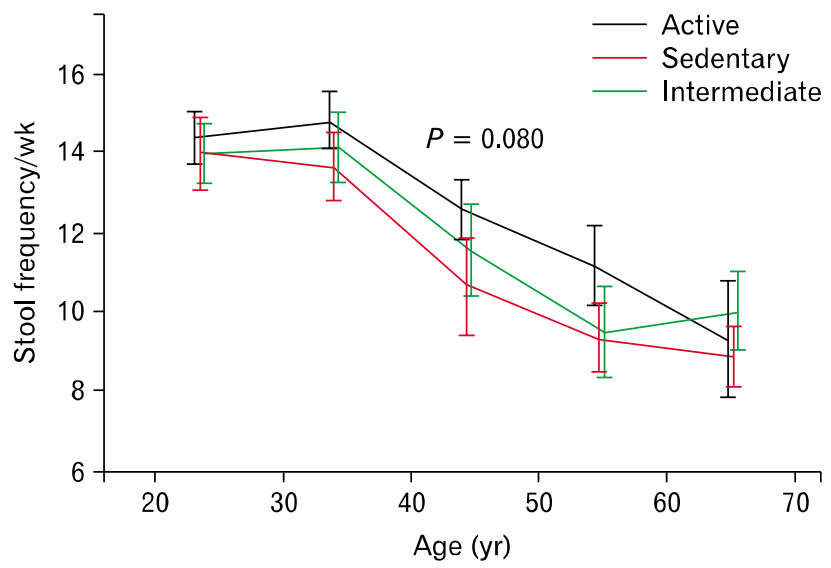

Figure 3. Aggregate plots showing. (A) Weekly stool frequency in relation to age of the study population (blue dotted line indicates the age at which stool frequency started reducing), (B) Weekly stool frequency with increasing age in relation to gender (blue dotted line indicates the age at which stool frequency started reducing), (C) Weekly stool frequency with increasing age in relation to diet and (D) Weekly stool frequency with increasing age in relation to physical activity.

mid-fourth decade of life both in male and female populations (Fig. $3 \mathrm{~A}$ and $3 \mathrm{~B}$ ). Number of subjects 35 years old or younger was 437/1,200 (36\%). Of 32 subjects who reported passing $\leq 3$ stools/week, all were female and only one of them was younger than 35 years.

\section{Relationship Between Diet and Stool Frequency and Form}

Two hundred and fifty-two (21\%), $395(33 \%)$ and 553 (46\%) subjects were vegetarian, non-vegetarian and occasional non-vegetarian, respectively. Vegetarians and occasional nonvegetarians passed stool more frequently than non-vegetarians (11.8 \pm 4.5 and $12.8 \pm 4.7$ vs. $11.3 \pm 4.7, P<0.05)$. Reduced stool frequency among non-vegetarian population was seen with increasing age (Fig. 3C).

\section{Relationship Between Physical Activity and Stool Frequency and Form}

Three hundred and seventy-nine (31.6\%), 464 (38.6\%) and 357 (29.7\%) reported active, sedentary and intermediately active life style, respectively. Subjects with active and intermediate activity tended to pass stool more frequently than sedentary people $(13.4 \pm 4.0$ and $12.3 \pm 4.5$ vs. $10.9 \pm 5.1, P=0.080)$. Reduced stool frequency among sedentary people tended to be seen with increasing age (Fig. 3D).

\section{Multivariate Analysis}

On multivariate analysis, female gender $(<0.001)$ and age 
$>35$ years $(<0.001)$ were independent predictors of passing $\leq 3$ stools per week but vegetarianism and physical activity were not significant.

\section{Discussion}

The present study showed that an apparently healthy study population from eastern India passed 14 stools/week (range 2-42) and the predominant form was Bristol type IV. On multivariate analysis, female gender and age $>35$ years were independent predictors of passing $\leq 3$ stools per week.

Bowel habit varies widely in different population across the world. ${ }^{6,7}$ In Western population, a stool frequency between 3/week to 3/day is considered normal. ${ }^{1,9}$ This is the basis for an older frequency-based definition of constipation, which suggested that a stool frequency less than $3 /$ week should be considered as constipation. ${ }^{10}$ However, this definition may not apply widely in different parts of the world including Asia as several studies showed that frequency of defecation to be higher in several Asian populations. ${ }^{14,15}$ Chen et $\mathrm{al}^{20}$ from Singapore found that most respondents (59\%) in their cross-sectional study reported bowel movement about once a day. Average stool weight in 514 healthy Indians older than 15 years was $311 \mathrm{~g}$ per day. ${ }^{16} \mathrm{In}$ contrast, stool weight greater than $200 \mathrm{~g}$ per day is diagnostic of diarrhea in Western population. ${ }^{21}$ In some non-Asian population also, a high frequency of bowel movement has been reported. In a Nigerian study on 1,115 adolescent subjects, $77 \%$ passed 1 stool/day, $17 \%$ once on each alternate day and only $5 \%$ passed once in $>3$ days. ${ }^{22}$ A postal survey from New Zealand showed the normal frequency of bowel motions was 2-17 per week in their general population. ${ }^{23}$ Bassotti et $\mathrm{al}^{4}$ from Italy reported a mean defecation frequency of $1.00 \pm 0.4$ /day. In the British study from East Bristol, once daily bowel movement occurred only in a minority in both the sexes. ${ }^{1}$ In this study, they found that less than once daily bowel habit was less common than a more than once daily among men ( $14.4 \%$ vs. $47.8 \%$ respectively, $P<$ $0002)$, though in women they were equally prevalent $(31.6 \%$ and $32.7 \%){ }^{1}$ In the East Bristol study, type 4 stool form predominated in both sexes (48.6\% in males and $46.1 \%$ in females). ${ }^{1}$ Current data showed that among an eastern Indian population, mean bowel movement was 14/week, which is much higher than that reported from most Western countries. ${ }^{1,9}$ Though this study is from eastern India, it is possible that the bowel pattern in other parts of India may be similar. Regional difference in stool form in India has never been studied. However, we do not expect it to be widely different as in an earlier pan-Indian study on 4500 community subjects, stool frequency was reported to be somewhat similar ( $>3$ stools/day, 167 subjects [3.7\%]; 3 stools/day, 242 [5.4\%]; 2 stools/day, 1,535 [34\%]; 1 stool/day 2,520 [56\%]; and $\leq 3$ stools/week $[43,1 \%]$ ). Stool form in Indian population was not studied earlier. Since this study presents normal bowel frequency and form in an apparently healthy Indian population, these data should be taken into consideration while defining constipation in this population.

Differences in gut transit time, dietary variation including fiber intake and consumption of non-vegetarian foods such as meat have been suggested to explain variation in stool frequency among different areas of the world is several earlier studies. ${ }^{16,24-27}$ However, in current study, dietary factors were not significant on multivariate analysis. This observation is in contrast to earlier studies. Davies et $\mathrm{al}^{28}$ in their study on bowel function measurements of individuals with different eating patterns showed all measurements of bowel function were significantly correlated with total dietary fiber. In this study, bowel habit was assessed in 51 subjects. A group of seventeen subjects (10 females, 7 males) each consumed omnivorous, vegan and vegetarian diet, which is associated with mean fiber intake of 23, 37 and $47 \mathrm{~g}$, respectively. Mean gut transit time was comparable among the 3 groups of subjects. Vegans passed softer and more frequent stools. Increasing dietary fiber was associated with shorter transit, more frequent stools and softer forms (mean transit time, frequency of defecation/24 hour, wet weight of feaces in $\mathrm{g} / 24$ hour of omnivorous $[51.8 \pm 19.4,1.0 \pm 0.2$ and $153 \pm 79]$, vegeterian $[48.5 \pm$ $27.2,1.2 \pm 0.5$ and $168 \pm 56]$ and vegans $[44.7 \pm 21,1.7 \pm$ 0.9 and $225 \pm 91]$ respectively). Men produced a greater quantity of softer, less formed feces than women. ${ }^{28}$ Study from UK showed mean bowel frequency was higher in vegetarians (10.5 in men, 9.1 in women) and especially in vegans (11.6 in men, 10.5 in women) compared with participants who ate meat (9.5 in men, 8.2 in women) supports our finding. ${ }^{29}$ On multivariate analysis, diet did not influence bowel habit in contrast to age and gender, suggesting the latter two factors to be more important. Fast transit time, ${ }^{30}$ and higher physical activity ${ }^{19}$ are known to increase stool frequency. In an earlier pan-Indian study on 4,500 subjects, 99\% passed at least one stool per day. ${ }^{15}$ Cultural factors also influence bowel habit. Quite early in their life, children in some parts in India, including the region where the current study was undertaken are exposed to the adage "He who defecates twice a day; remains healthy - keeps the doctor away."

Lower stool frequency, harder stool forms and constipation 
have been reported to be commoner among females than males. ${ }^{3,31}$ Women had fewer bowel movements on average than men, and were less likely to have daily bowel movements. ${ }^{29}$ In another study from London, females less often passed stool than males. ${ }^{9}$ This has been explained by the hypothesis that female sex hormones reduce gut transit. ${ }^{17}$ However, our finding of decreasing stool frequency with increasing age, particularly among females, cannot be explained by the hormonal hypothesis. Another study from Germany found that mean stool frequency was $1.02 /$ day, with $95 \%$ of the studied normal population having between 2 stool per day and one every 2 day, and becoming less frequent with age. ${ }^{32}$ One possible explanation for reduction in stool frequency with aging among female population could be related to the development of pelvic floor disorders with aging among females. This can be further compounded by the effect of parturition on pelvic floor. Vaginal delivery and higher parity increased the risk of both urinary and defecatory symptoms of pelvic floor dysfunction. ${ }^{33}$ This is further supported by the finding that reduction in stool frequency started at the middle of fourth decade (Fig. 3B), when female hormones are reduced; by this age, however, a large proportion of female population would have undergone parturition. This issue requires further study.

In conclusion, healthy Indian passed 14 stools per week and predominant form was Bristol type IV. These data should be taken into consideration while defining constipation in India and other geographical areas with similar bowel habit. Female gender, sedentary life-style and non-vegetarianism were associated with lesser stool frequency and harder forms; on multivariate analysis, female gender and age $>35$ years were independent predictors of passing $\leq 3$ stools per week. Older age was associated with lesser stool frequency, particularly among female subjects. These factors may influence epidemiology and pathogenesis of constipation in Indian population.

\section{References}

1. Heaton KW, Radvan J, Cripps H, Mountford RA, Braddon FE, Hughes AO. Defecation frequency and timing, and stool form in the general population: a prospective study. Gut 1992;33:818-824.

2. Sandler RS, Drossman DA. Bowel habits in young adults not seeking health care. Dig Dis Sci 1987;32:841-845.

3. Everhart JE, Go VL, Johannes RS, Fitzsimmons SC, Roth HP, White LR. A longitudinal survey of self-reported bowel habits in the United States. Dig Dis Sci 1989;34:1153-1162.

4. Bassotti G, Bellini M, Pucciani F, et al. An extended assessment of bowel habits in a general population. World J Gastroenterol 2004;10: 713-716.
5. Chang FY, Lu CL, Chen TS. The current prevalence of irritable bowel syndrome in Asia. J Neurogastroenterol Motil 2010;16:389400 .

6. Cummings JH, Bingham SA, Heaton KW, Eastwood MA. Fecal weight, colon cancer risk, and dietary intake of nonstarch polysaccharides (dietary fiber). Gastroenterology 1992;103:1783-1789.

7. Gwee KA, Lu CL, Ghoshal UC. Epidemiology of irritable bowel syndrome in Asia: something old, something new, something borrowed. J Gastroenterol Hepatol 2009;24:1601-1607.

8. Daniyam CA, Malu AO, Okeke EN, Lawal OO. Bowel habits of urban and rural populations on the Jos, Plateau, Nigeria. West Afr J Med 2011;30:182-187.

9. Connell AM, Hilton C, Irvine G, Lennard-Jones JE, Misiewicz JJ. Variation of bowel habit in two population samples. Br Med J 1965;2:1095-1099.

10. Wald A. Pathophysiology, diagnosis and current management of chronic constipation. Nat Clin Pract Gastroenterol Hepatol 2006; 3:90-100.

11. Ghoshal UC, Abraham P, Bhatt C, et al. Epidemiological and clinical profile of irritable bowel syndrome in India: report of the Indian Society of Gastroenterology Task Force. Indian J Gastroenterol 2008;27:22-28.

12. Perveen I, Hasan M, Masud MA, Bhuiyan MM, Rahman MM. Irritable bowel syndrome in a Bangladeshi urban community: prevalence and health care seeking pattern. Saudi J Gastroenterol 2009; 15:239-243

13. Masud MA, Hasan M, Khan AK. Irritable bowel syndrome in a rural community in Bangladesh: prevalence, symptoms pattern, and health care seeking behavior. Am J Gastroenterol 2001;96:15471552.

14. Fang X, Lu S, Pan G. [An epidemiologic study of bowel habit in adult non-patient population in Beijing area.] Zhonghua Yi Xue Za Zhi 2001;81:1287-1290. [Chinese]

15. Adibi P, Behzad E, Pirzadeh S, Mohseni M. Bowel habit reference values and abnormalities in young Iranian healthy adults. Dig Dis Sci 2007;52:1810-1813

16. Tandon RK, Prasad N, Gupta NC, Tandon BN. Stool weight and transit time in north Indians. J Assoc Physicians India 1976;24:807810

17. Bhatia SJ, Reddy DN, Ghoshal UC, et al. Epidemiology and symptom profile of gastroesophageal reflux in the Indian population: report of the Indian Society of Gastroenterology Task Force. Indian J Gastroenterol 2011;30:118-127.

18. Ghoshal UC, Abraham P, Bhatia SJ, et al. Comparison of Manning, Rome I, II, III and Asian criteria: report of a multi-centric Indian irritable bowel syndrome (MIIBS) study. Indian J Gastroenterol 2013 (In press)

19. Heaton KW, Ghosh S, Braddon FE. How bad are the symptoms and bowel dysfunction of patients with the irritable bowel syndrome? A prospective, controlled study with emphasis on stool form. Gut 1991;32:73-79.

20. Chen LY, Ho KY, Phua KH. Normal bowel habits and prevalence of functional bowel disorders in Singaporean adults - findings from a community based study in Bishan. Community Medicine GI Study Group. Singapore Med J 2000;41:255-258.

21. Fernández-Bañares F, Esteve M, Salas A, et al. Systematic evalua- 
tion of the causes of chronic watery diarrhea with functional characteristics. Am J Gastroenterol 2007;102:2520-2528.

22. Akinbami FO, Okereke JO, Orimadegun AE. The bowel habits of adolescents in Nigeria. Trop Gastroenterol 2010;31:295-302.

23. Lynch AC, Dobbs BR, Keating J, Frizelle FA. The prevalence of faecal incontinence and constipation in a general New Zealand population; a postal survey. N Z Med J 2001;114:474-477.

24. Okubo H, Sasaki S, Murakami K, et al. Dietary patterns associated with functional constipation among Japanese women aged 18 to 20 years: a cross-sectional study. J Nutr Sci Vitaminol (Tokyo) 2007;53: 232-238.

25. Sandler RS, Jordan MC, Shelton BJ. Demographic and dietary determinants of constipation in the US population. Am J Public Health 1990;80:185-189.

26. Wong ML, Wee S, Pin CH, Gan GL, Ye HC. Sociodemographic and lifestyle factors associated with constipation in an elderly Asian community. Am J Gastroenterol 1999;94:1283-1291.

27. Ghoshal UC, Sengar V, Srivastava D. Colonic transit study technique and interpretation: can these be uniform globally in different populations with non-uniform colon transit time? J Neurogastroen- terol Motil 2012;18:227-228.

28. Davies GJ, Crowder M, Reid B, Dickerson JW. Bowel function measurements of individuals with different eating patterns. Gut 1986;27:164-169

29. Sanjoaquin MA, Appleby PN, Spencer EA, Key TJ. Nutrition and lifestyle in relation to bowel movement frequency: a cross-sectional study of 20630 men and women in EPIC-Oxford. Public Health Nutr 2004;7:77-83.

30. Ghoshal UC, Ghoshal U, Ayyagari A, et al. Tropical sprue is associated with contamination of small bowel with aerobic bacteria and reversible prolongation of orocecal transit time. J Gastroenterol Hepatol 2003;18:540-547.

31. Talley NJ, Weaver AL, Zinsmeister AR, Melton LJ 3rd. Functional constipation and outlet delay: a population-based study. Gastroenterology 1993;105:781-790.

32. Giebel GD, Mennigen R, Burde C. Attitude at stool: what is the norm? Coloproctology 1985;17:99-104.

33. Kepenekci I, Keskinkilic B, Akinsu F, et al. Prevalence of pelvic floor disorders in the female population and the impact of age, mode of delivery, and parity. Dis Colon Rectum 2011;54:85-94. 